\title{
Expletives as solidarity signals in FTAs on the factory floor ${ }^{\text {th }}$
}

\author{
Nicola Daly, Janet Holmes*, Jonathan Newton, Maria Stubbe \\ School of Linguistics and Applied Language Studies, \\ Victoria University of Wellington, PO Box 600, Wellington, New Zealand
}

Received 29 April 2003; received in revised form 2 December 2003; accepted 12 December 2003

\begin{abstract}
Drawing on Politeness Theory and the Community of Practice model, we examine the uses and functions of the expletive fuck in interaction between workers in a New Zealand soap factory work team. The factory team was extensively recorded in their daily interactions to obtain a corpus of $35 \mathrm{~h}$ of authentic workplace talk from which a small number of paradigmatic interactions are selected for discussion in this paper. Particular attention is given to the way in which the expletive fuck is used in two face threatening speech acts, direct complaints and refusals, and its contrasting function in the speech act of whingeing. The analysis focuses on the complex socio-pragmatic functions of fuck and its role as an indicator of membership in a specific community of practice.
\end{abstract}

(C) 2004 Elsevier B.V. All rights reserved.

Keywords: Workplace discourse; Complaints; Refusals; Community of practice; Swearing; Face threatening speech acts

th The Language in the Workplace Project Research team includes core members Janet Holmes (Director), Maria Stubbe (Research Fellow), Bernadette Vine (Corpus Manager), Meredith Marra (Research Officer), as well as Nicola Daly, Jonathan Newton, Derek Wallace, Pascal Brown and a number of Research Associates. We would like to express our appreciation to the staff at Unilever Australasia who generously allowed us to observe and record their workplace interactions and the Research Assistants who transcribed the data. Particular thanks are due to Megan Ingle who did the fieldwork at the factory, and Tina Chiles, who assisted with the preparation of this article. The research was supported by grants from the Victoria University Research Fund and the New Zealand Foundation for Research Science and Technology.

* Corresponding author. Tel.: + 64-4-463-5614; fax: + 64-4-463-5604.

E-mail address: janet.holmes@vuw.ac.nz (J. Holmes). 


\section{Introduction}

Speech act research over the last two decades has encompassed an increasingly broad range of types of speech act. From an initial focus on directives (e.g. ErvinTripp, 1976; Brown and Levinson, 1978; Bellinger and Gleason, 1982), researchers proceeded to examine positively affective speech acts, such as compliments and apologies (eg. Olshtain and Cohen, 1983; Holmes, 1986; Herbert, 1989), as well as more negatively affective acts, such as disagreements (Blum-Kulka et al., 2002; Georgakopolou, 2001; Scott, 2002). This paper reports on research which contributes to the latter group, by exploring the ways in which the speech acts of complaint and refusal are expressed in a particular social context.

The decision to focus on these speech acts was made on the basis of a detailed survey of our data which revealed complaints and refusals to be both frequent in the data and to represent particularly salient instances of negatively affective speech acts. A review of the literature indicates that these speech acts have predominantly been examined using data from middle class speech communities, such as university staff and students (e.g. Besson et al., 1998; Liao and Bresnahan, 1996; Owen, 1983; Stevens, 1993). There is very little authentic data on complaints in the workplace, none on complaints in the New Zealand workplace, and no data of which we are aware on authentic refusals in workplace contexts. Moreover, most of the data which has been collected to illustrate the ways in which people express these speech acts comprised written data has elicited using some variant of the discourse completion task (DCT), as popularised by the influential Cross-Cultural Speech Act Research project (Blum-Kulka et al., 1989). The research reported in this paper, by contrast, is based on authentic recorded spoken data collected in a factory environment by those engaged in their normal everyday workplace interaction on the factory floor (Stubbe, 2001; Stubbe and Ingle, 1999). Such data reveals the complex ways in which these speech acts are negotiated over several turns.

Advocating a multidisciplinary approach to discourse analysis, Lakoff (2001: 212) observes that "[t]hrough concentration on a particular speech act located in a specific cultural and societal time and place, we can come to understand a great deal about who we are, what we want, and the rules and assumptions that bind us together as a society." Our examination of the way complaints and refusals are expressed and interpreted in a particular workplace setting, namely on the factory floor, provides a specific example confirming Lakoff's point. The analysis provides insights into the way language is used in this particular socio-cultural setting, and, in particular, illuminates the complexity of what is considered "polite" behaviour in different communities of practice.

\subsection{The Community of Practice model}

In this paper we have adopted a community of practice (CofP) framework for exploring distinctive aspects of politeness within work-team culture. The CofP approach focuses on what members do - the practice or activities which indicate that they belong to the group, and the extent to which they belong. It also takes 
account of the attitudes, beliefs, values and social relations which underlie their practice, and provides a framework for examining the ways in which individuals construct roles and relationships within the parameters established as acceptable by the group with which they work.

The linguistic manifestations of a shared repertoire provide a basis for describing how a distinctive workplace "culture" is constructed through interaction. Wenger (1998: 73) identifies three criterial features of a CofP: (i) mutual engagement; (ii) a joint negotiated enterprise; and (iii) a shared repertoire of negotiable resources accumulated over time.

Wenger also identifies a number of more specific "constitutive characteristics" of a CofP, some of which lend themselves to the analysis of patterns of interaction and, more specifically, of discourse; these include shared ways of engaging in doing things together and discursive ways of sustaining relationships and displaying group membership, such as social talk, small talk, and the use of humour (1998: 125-126). Over time, workplace communities construct a unique set of discursive practices from the resources available to them, compatible with other aspects of the way they work together. These shared practices, and the ways in which individuals conform to or challenge the group's norms, contribute to the construction of a particular community of practice.

\subsection{Politeness theory}

The concept of a face threatening act (FTA) derives from Politeness Theory, as first proposed by Brown and Levinson (1978), and extensively developed since then. While this theory has attracted considerable criticism over the last two decades (see, for instance, Brown and Levinson, 1987; Eelen, 2001; Holmes and Stubbe, 2003a), it nonetheless continues to provide a useful framework for the analysis of discourse and speech acts. The concept of "face" can be defined as "the positive self-value a person effectively claims for himself [sic]" (Goffman, 1967: 5), or "every individual's feeling of self-worth or self-image" (Thomas, 1995: 169). Politeness Theory identifies two aspects of individuals" "face", namely, their positive and negative face needs. Positive face needs include individuals' need to be approved of and liked by others, and to have their wishes and desires shared and respected. Negative face needs relate to individuals' need for privacy and distance from others, and to have their autonomy and independence respected. Politeness Theory suggests that in order to ameliorate the impact of an FTA which threatens the negative face of the addressee or hearer, the speaker will make use of such negative politeness strategies as being indirect, adopting hedging devices, or apologising. Positive politeness strategies, on the other hand, emphasise friendliness towards and solidarity with the speaker, and these are used more generally (i.e., in response to both positive and negative FTAs). Brown and Levinson (1987) suggest a number of forms of positive politeness, including the use of in-group identity markers, address forms, jargon and slang. Clearly, complaints and refusals, the subjects of this paper, constitute canonical instances of speech acts which overtly threaten both the negative and positive face needs of the addressee. 


\subsection{Defining a complaint}

According to Clyne, complaints "are speech acts in which disappointment or a grievance is expressed" (1994: 49). Two categories of complaint can be distinguished: direct complaints and whinges. In the first category, direct complaints ${ }^{1}$ (Boxer, 1993), the addressee is held responsible for the perceived offence and is expected to acknowledge or change the undesirable state of affairs. A direct complaint involves an explicit or implicit accusation and at least one explicit or implicit directive (Clyne, 1994: 54). By stating or implying that the addressee is responsible for a perceived offence, direct complaints threaten the addressee's positive face, i.e. the need to be approved of and liked. Moreover, by stating or implying that the addressee should undertake some action to change the undesirable state of affairs, the complaint impinges on the addressee's negative face, or their need to be unimpeded and autonomous.

The second category of complaint, the indirect complaint (Boxer, 1993) or "whinge", is a "long or repeated expression of discontent not necessarily intended to change or improve the unsatisfactory situation" (Clyne, 1994: 49). ${ }^{2}$ Whinges differ from direct complaints in that the addressee is not primarily held responsible for the perceived offence (Boxer, 1993); instead, whinges function to provide emotional release, or to off-load negative affect, rather than provoking action to redress the offence. In other words, whinges are not prototypical FTAs; rather, they are typically ways of establishing rapport with others. In his research investigating communication in Australian factories, Clyne (1994) demonstrated that whinges in workplace settings usually took place between people of equal or near equal status, and functioned as a kind of phatic communion which promoted solidarity between interactants. Whinges are thus a useful site for illustrating means by which workplace participants express solidarity.

\subsection{Defining a refusal}

Refusals are typically the second part of a pair of adjacent utterances; the core component of a refusal is a denial or an expression of unwillingness to comply with a previous request, invitation or offer. Kline and Floyd (1990: 460) define a refusal as "an attempt to bring about behavioural change by encouraging the other to withdraw his/her request", and they identify the core component as clearly indicating "opposition to granting a request". A refusal is without doubt, then, a facethreatening and negatively affective speech act.

Refusals are highly face threatening speech acts because they involve the rejection of a request which the communicator felt was legitimate to make. The refuser is thus torn between resisting an undesirable request and supporting the requester's self image. According to Politeness Theory, this conflict may be resolved by constructing a refusal which includes linguistic elements addressing the positive face needs of the

\footnotetext{
1 Also known as instrumental complaints (Alicke et al., 1992) and exercitive complaints (Clyne, 1994).

2 Also known as non-instrumental complaints (Alicke et al., 1992).
} 
requester (Besson et al., 1998). In other words, the refuser is expected to address the requester's need to be supported in assessing the legitimacy of the request, and the theory predicts that in such an interaction the refuser will make use of positive politeness strategies. The reality is not always so predictable, as we demonstrate below.

Since complaints and refusals can be considered paradigmatic instances of FTAs, Politeness Theory predicts that they will be accompanied by one or more politeness strategies designed to reduce the threat to the face of the hearer. A whinge, by contrast, is typically an indirect solicitation of sympathy, and is generally addressed to someone of similar status; whinges tend to co-occur, with one person endorsing and often mirroring another's whinge. Hence whinges often function as a means of constructing solidarity between co-workers.

Given the different functions of complaints and refusals on the one hand, and whinges on the other, the pervasive occurrence of fuck across these contrasting speech acts provides the basis for exploring this expletive's complex functions in this corpus of workplace interaction.

\subsection{Fuck}

While a range of expletives were used by the factory team observed for this study, fuck was used most frequently and consistently across different speech acts; for this reason, it is the focus of this paper. In current usage, ${ }^{3}$ fuck has a range of meanings including "to have intercourse"(Orsman, 2001), and "to ruin" (eg. it was completely fucked), as well as more overtly expletive functions as an attention-grabbing particle (eg fuck! look at that), an insult (eg. fuck you!), and an intensifier (eg that's fucking marvellous). It is certainly a word that has the potential to cause offence in many contexts. The Collins Cobuild English Dictionary for Advanced Learners advises that "[f]uck is a rude and offensive word which you should avoid using" (Sinclair, 2001: 635).

Our analysis suggests that, in certain contexts, forms of fuck may serve to express positive politeness or solidarity, and may even function to mitigate or redress the strength of the face threat of refusals and complaints on the factory floor. In the words of the team coordinator, the use of expletives and jocular abuse by members of the team we studied "was a 'we know each [other] well thing' ...... no one really took offence" (pers. comm.).

\section{Purpose}

As mentioned above, when people engage in FTAs such as complaint and refusal, Politeness Theory predicts that they will adopt linguistic politeness strategies to

\footnotetext{
3 Fuck is a word of Indo-European origin, attested in Germanic from the 16th century (compare Modern German ficken to have intercourse and Modern Dutch fokken to breed (e.g. of cattle). In its original meaning, to strike (Hanks 1954), it may be related to Latin pungere to pierce, pugna fight (cf. English pugilist fist fighter).
} 
address the face needs of their addressees. The data we examined revealed that the precise ways in which such face needs were addressed by members of our focus factory team often made use of strategies that would not be predicted by Brown and Levinson's model. Indeed, the non-conventional nature of some of the strategies adopted by members of the factory team to attend to the face needs of others provides support for Eelen's argument that Politeness Theory can be critiqued as overtly "normative" in some respects (Eelen, 2001). In particular, strategies used to create solidarity and provide face-attention in relation to complaints and refusals in the factory context included various forms of the expletive fuck that might be conventionally expected to boost rather than attenuate the threat to face posed by these speech acts.

In sum, then, the purpose of this paper is three-fold: to show what authentic data from a NZ factory adds to our understanding of the way people express complaints, whinges and refusals in different social contexts; to illustrate the ways in which the expletive fuck functions as an in-group solidarity marker for a particular close-knit team with a largely Polynesian/Samoan membership; and finally, to suggest ways in which standard Politeness Theory needs to be revised to account for such data.

\section{Data Collection}

The data examined in this paper is taken from the corpus of the Wellington Language in the Workplace Project (Holmes and Stubbe, 2003a). In all work sites investigated in this project the methodology has been designed to give participants the maximum control possible over the data collection process. Typically, we ask a group of volunteers from the workplace to record a sample of their everyday workplace interactions over a period of a couple of weeks. In the factory environment, where machine noise threatened to drown out a good deal of the talk, some team members carried radio microphones which collected a good range of data. A fieldworker also first observed and took notes, and later recorded additional interactions as opportunities arose. Further relevant contextual information was collected in follow-up interviews with participants (Stubbe, 2001).

The data discussed below is taken from recordings of one close-knit production team in a New Zealand soap factory who were given the pseudonym The Power Rangers. The team had 20 core workers, most of whom were men (there were four women), representing four different ethnic groups, namely Samoan, Mäori, Tongan and Pakeha (i.e. European New Zealanders). Most of their communication was in English, though Samoan was also used on occasion. The team was set up to be selfmanaging with a team coordinator whose role was seen, on paper at least, as 'first among equals'. The team included packers who were working on a production line putting soap powder into boxes, and manufacturers who co-ordinated the production of powders using computers in a control room. The two groups had separate daily briefing sessions and irregular contact with each other during their 12-h shifts. Many of the team had worked together for a very long time and team members had developed a strong sense of group identity. They were highly motivated to out-perform 
other teams within the factory, and to meet quality and safety requirements (Stubbe, 2000a; 2000b).

Thirty-five hours of recordings have so far been transcribed from the interactions of this factory team. The transcriptions were annotated with detailed contextual notes providing information on location, type of talk (e.g. work talk, social talk), topic, tone, brief summaries of the speech event (e.g. Ginette reports training progress of team members), speech act labels (e.g. direct complaint, instruction) and participant information. This coding system allowed for rapid searches through the data for salient examples of specified situational variables or speech events/acts.

\section{Data Analysis}

In what follows, we focus on the ways in which members of the Power Rangers team made use of fuck in accomplishing the FTAs of complaint and refusal as well as the contrasting act of whingeing. While we had a considerable amount of data at our disposal, we chose to focus on a small set of prototypical examples of the speech acts in question so as to explore the situational and interpersonal factors that shaped interactions within this work team. Thus, in the following discussion we examine four sequences; one direct complaint, two whinges and one refusal. The participants, topics, and interactions selected for exemplification are representative of those found in the larger sample.

\subsection{Direct complaint}

Example 1 is an instance of a direct complaint where the speaker, Russell, clearly holds the addressee, Lesia, responsible for the perceived offence, and appears to expect him to rectify matters. ${ }^{4}$ Russell is complaining to Lesia that he has been on the same packing line for a long time. Since Lesia is responsible for shift planning, he can change the packing line Russell works on.

\section{Example $1^{5}$}

Context: Russell, a Samoan/European male aged 25-29, is a packer. Lesia, a Samoan male aged 30-34, is also a packer, but has responsibility for shift planning.

1 Russell: fucking sick of this line (Lesia)

2 Lesia: [voc]

3 Russell: stuck here all the time

4 Lesia: if you I put you on that line you're getting worse

5 Russell: ( )

6 Lesia: fucking worse + slow like an old man

$7 \quad$ (all you have to just) ++

\footnotetext{
4 All examples use pseudonyms.

5 Transcription conventions are provided in the appendix.
} 
8 Russell: that's what I want +++

9 Lesia: if I put you on that line you falling asleep (6)

10 Russell: how much do we have to do on here

Like much authentic data, this is difficult to understand without a gloss. Moreover, machine noise often interferes with the audibility of the interaction, as indicated by the phrases in brackets which signal the transcriber's best rendition of a hard-tohear phrase. In essence, however, it is clear that Russell is complaining that he is fed up with being on this packing line (lines 1,3), while Lesia argues back that any other line would be worse because Russell would find it too slow and boring (lines 4,6,9).

Russell's direct complaint (line 1) can be classified as a face threatening act and so one might expect, according to Politeness Theory, that he would use some kind of linguistic politeness strategy to attenuate the impact of his complaint. In fact, rather than reducing the strength of his complaint, Russell uses the adjective fucking, thus apparently boosting or intensifying the insult value of his FTA. So although Russell is clearly complaining to Lesia, he does not use conventional linguistic politeness strategies to redress the implied threat to Lesia's positive face. Lesia does not accept Russell's complaint or offer to rectify it. He argues back and challenges Russell's position. He responds that any other packing line would be worse. Lesia uses fucking in a more predictable way than Russell, namely to intensify the adjective worse (line 6). While the use of expletives such as fucking between these team members may surprise newcomers to this workplace, its function as a pragmatic intensifier is more easily accounted for.

To accurately interpret the socio-pragmatic meaning of Russell's use of the word fucking it is necessary to draw on wider ethnographic information, as well as examining further examples of complaints produced by members of the Power Rangers production team. The interactive style and discourse of this team was quite distinctive within the soap factory; their particular blend of verbal humour, jocular abuse and practical jokes contributed to a unique team culture, and generally helped to create positive relationships within the team (see also Stubbe, 2000a; Holmes and Marra, 2002). Team members used a very lively communicative style, characterised by uninhibited swearing and friendly insult; they were constantly joking around and "having each other on". Ethnographic data and observation indicated that these strategies were functioning as markers of solidarity in team interactions. As such, they functioned alongside other more conventional positive politeness strategies such as the use of nicknames, address terms such as bro and mate, in-group talk and gossip. Overall, then, the team's interactive style functioned to construct and reinforce a strong orientation to team morale, and contributed to their distinctive reputation, which sat well alongside their status as the top-performing team. Such playful, yet highly competitive, strategies for building solidarity are well-documented as common characteristics of all-male groups (e.g. Kuiper, 1991; Kiesling, 2001; Coates, 2002). All this suggests that expletives such as fucking function for members of this team as solidarity markers, and thus as forms of positive politeness. Further support for this interpretation is provided when we examine (below) instances of the second type of complaint, namely the whinge. 
A second point worth noting in relation to the realisation of this direct complaint is the fact that it takes several turns to fully work through. Russell takes two lines $(1,3)$ simply to express his dissatisfaction, and then he and Lesia negotiate their way through the complaint in a complex manner, as described. Authentic recorded interaction is not neat and tidy. By contrast, typical discourse completion tasks provide a single response space for respondents to provide what they think they would say in a situation where they are asked to "complain". This contrast between the kind of data produced by people in genuine workplace contexts, as opposed to the data elicited by written discourse completion task questionnaires is discussed in more detail in Beebe and Cummings (1996), Frescura (1995).

\subsection{Whinges}

As discussed above, whinges differ from direct complaints in that the addressee is not held responsible for the perceived offence. They provide a means of off-loading negative feelings in a safe environment, and since they typically elicit sympathy, they function to build rapport with others.

Example 2 involves two male team members who are close friends. With Lesia, another team member, they form a tight-knit social sub-group within the Power Rangers. Russell has been doing a lot of overtime to earn extra money and his workmates have been teasing him about this. In Example 2 he is whingeing that he was underpaid the previous week.

\section{Example 2}

Context: Robert, a Samoan male aged 25-29, working as a manufacturer, is talking to Russell, a Samoan/European male also aged 25-29, who is a packer.

1 Russell: fuck man I got a short pay last week again ++

2 eight ninety + that's only for three days ++

3 Robert: ( ) + eight ninety? + stick it up your fucking arse

4 you did overtime you cunt +

5 Russell: oh yeah too high

6 Robert: (yep) + you get that this week eh +

$7 \quad$ fuck I won't get mine till next week

8 Russell: oh yeah Sunday eh

9 Robert: I did yesterday

10 Russell: yeah +

11 Robert: Sunday Sunday

Russell opens his whinge with fuck man, an attention-grabbing device, and goes on to complain that his pay was low last week (line 1). Rather than acknowledging and supporting Russell's whinge, Robert responds humorously by challenging the information in Russell's complaint (eight ninety? + stick it up your fucking arse...), a response which is not what might be expected between two workmates on good terms. Robert then becomes the whinger, matching or mirroring Russell's whinge 
with one of his own; he complains that he won't get his pay till the next week (line 7). He too introduces his whinge with an emphatic fuck. Russell, now the responder, agrees and commiserates oh yeah Sunday eh (line 8). The exchange is clearly a friendly one overall. Robert's "mirroring" behaviour is classic solidarity construction work as identified by Coates (1996) in her analysis of women talk; and Russell's response (line 8) is quite evidently an instance of standard sympathetic positive feedback. ${ }^{6}$

Once again, then, we have instances of complaints which appear to be intensified rather than attenuated, although since these are whinges rather than direct complaints, the face of the addressee is not under direct threat. Once again, too, forms of the expletive fuck are used to modify the relevant speech acts. Since the whinges clearly serve as expressions of solidarity between the two men, it seems evident that forms of fuck serve a similar function. In this context, the use of expletives which would be considered offensive in other contexts serves as evidence of the close relationship between the men. These men are on such good terms that they can swear at each other, not only with impunity, but with positive affect. Forms of fuck appear to act as markers of solidarity and positive politeness for members of this community of practice. In particular, we suggest that in Robert's challenge to Russell's whinge, stick it up your fucking arse, the use of fucking can be interpreted as a solidarity symbol, a positive politeness strategy. It could also be argued that as such it serves to mitigate rather than intensify his bald and face-threatening contradiction of Russell's claim.

This interpretation of the function of expletives as solidarity signals for this particular community of practice is further supported when we examine interactions between other members of the Power Rangers. Example 3 involves two female team members.

\section{Example 3}

Context: Ginette, a Samoan aged 30-34 years, who is the team coordinator, is talking on the packing line to Sue, a Pacific Island female aged 45-49, another member of the Power Rangers team.

$\begin{array}{lll}1 & \text { Ginette: } & \text { about eleven + okay } \\ 2 & \text { Sue: } & \text { ( ) (15) } \\ 3 & \text { Ginette: } & \text { that dumb mole that did my laminating }++ \text { dumb bitch }++ \\ 4 & & \text { Rylie }+ \text { all the stuff I want laminated she hasn't done it yet } \\ 5 & & \text { but she's done two copies of the ones down there }+ \\ 6 & \text { I saw a whole heap and I thought oh yeah she's done it all } \\ 7 & \text { and I've just been through (it and) } \\ 8 & \text { [high voice]: where the fuck's all that stuff: }+\end{array}$

\footnotetext{
6 This example clearly illustrates a point emphasised in the recent language and gender literature (eg see Holmes and Stubbe 2003b), namely, that such discourse strategies are more usefully analysed along the dimensions "feminine" and "masculine", rather than being described as "women's talk" and "men's talk".
} 
16 Sue:

21 Sue:

Ginette is whingeing that an assistant has not done some laminating that has been requested. In her first and extended turn, her descriptive whinge makes use of several expletives and insults: dumb bitch (line 3), where the fuck's all that stuff (line 8), fuck man (line 12), and you can BLOODY have her back (line 13). Ginette then continues using expletives in her two subsequent turns as she elaborates her complaint about the assistant Rylie: bloody Rylie (line 18) and bloody hell I'm fucked off (line 22). Ginette's addressee, Sue, is a member of the Power Rangers team on the packing line. Her response is sympathetic: she answers Ginette's query about Millie (lines 1617) and responds with a laugh (line 21) to Ginette's cynical analysis of why she has been assigned Rylie as her assistant. Sue allows Ginette to let off steam about the situation in a supportive environment. Team mates regularly have a moan to each other; whingeing to a sympathetic co-worker both reflects and constructs the close relationship between team members, thus consolidating the team's solidarity. In this context, expletives cement and emphasise team solidarity. Ginette's use of expletives in example 3 would certainly cause offence and raised eyebrows in many other workplaces, especially when the expletives are used by women (see Holmes and Stubbe, $2003 \mathrm{~b}$ for a detailed discussion of this point). Here, they function to confirm Sue as a member of the in-group, the Power Rangers team.

These examples provide authentic data to illustrate the difference between direct complaints and whinges. Whinges are manifestations of solidarity; they tend to occur between people who know each other well since they are typically aimed at eliciting sympathy and understanding. Because of this, these examples also provide some insight into the socio-pragmatic functions of forms of fuck in the factory workplace we were researching. Widespread use of fuck by this work team distinguished it from other similar teams and suggest that in addition to its standard functions as an intensifier and attention grabbing expletive, it is serving to signal in-group solidarity within a particular community of practice. We turn next to an examination of its function in relation to another face-threatening act, the refusal. 


\subsection{Refusals}

As noted above, a refusal is a responsive speech act; it is typically the second component in a minimally two-part sequence (see Holmes and Daly forthc.). And, whether expressed explicitly or implicitly, a refusal is fundamentally a facethreatening act which challenges the positive face needs of the requester by implying some level of disagreement with the addressee. Politeness Theory predicts therefore that a refusal, if it is explicitly expressed, will include linguistic devices which address the positive face needs of the requester.

Much previous research on refusals tends to confirm this prediction. This research covers a range of social contexts, including Scottish parents' refusals of their children's requests (Wootton, 1981), written rejections of students' applications for membership of an organization (Saeki and O'Keefe, 1994), and written responses refusing a date (Besson et al., 1998). The patterns seen in interactions recorded in a blue-collar workplace, however, provide a rather different and more complex picture, as the examples below illustrate.

Example 4 is an example of a request by the packer, Russell, and an implicit refusal of Russell's request by his team coordinator Ginette.

\section{Example 4}

Context: Ginette, a Samoan aged 30-34 years, Power Rangers team coordinator, talking to Russell, a packer who is a Samoan European aged 25-29.

1. Russell: can you get me one please [in Samoan] :fa'amolemole: [please]

2. Ginette: you get one

3. Russell: ah you're not doing anything

4. Ginette: you go and get one

5. Russell: fuck it +++ fuck you go get your fucking legs out here (fatters)

6. Ginette: why didn't you get one before I talked to you about that yesterday

7. Russell: because we're busy + I got to get all that out of the way

Russell's initial request can you get me one please fa'amolemole' (line 1) appears on the surface to be expressed very politely. It involves conventional indirectness since Russell uses a modal interrogative form can you rather than an imperative (get me one), and he also uses the conventional particle please, not just once, but twice, the second time in Samoan, his and Ginette's first language. Given the close relationship that we know exists between these team members, metaphorically reinforced by the repetition of please in Samoan, we can interpret this as tongue-in-cheek conventional politeness - a send-up rather than a genuinely respectful request. This interpretation is confirmed by what follows. Ginette's response constitutes an implicit refusal, intensified or exacerbated by the fact that it takes the form of a bald-on-record directive with no mitigating features you get one (line 2). In other words, Ginette's clear directive to Russell to fulfil his own request quite unambiguously indicates that she is refusing to do so.

The exchange continues in this contestive style with Russell's in-your-face challenge to Ginette's response, you're not doing anything (line 3). Unmitigated 
confrontational behaviour of this kind is common between close friends and intimates but it is not what many would expect between co-workers, nor between a worker (Russell) and a supervisor (Ginette). It is, however, perfectly consistent with our ethnographic data on the interactional style of the Power Rangers team, as noted above. In the same vein, Ginette re-iterates her bald refusal (line 4), to which Russell responds with a group of expletives fuck it fuck you go get your fucking legs out here (line 5). This utterance provides an illustration of most of the conventional functions of fuck referred to in the introduction, namely an expression of exasperation, fuck it, an insult, fuck you, and an intensifier fucking legs.

Ginette's response to the string of expletives gives no indication that she is surprised or offended by the expletives. Rather, she gives the kind of response one might expect between family members rather than co-workers, namely, why didn't you get one before I talked to you about that yesterday (line 6) i.e. implying "you have got yourself into this situation, serves you right, why should I help". Clearly, she does not regard Russell's language as unusual or worth comment or reaction.

Example 4 thus provides another example of the use of forms of fuck in the context of an FTA, a refusal. Russell makes a request of his supervisor which clearly impinges on her negative face. Perhaps because she is his team leader, and thus has more power and status, or perhaps because she is treating him as an equal, a coworker in a close-knit community of practice, Ginette quickly and directly refuses the request with no mitigating strategies, and with no explanation or apology. This is certainly not standard polite refusal behaviour as described by Kline and Floyd (1990), or the behaviour reported in previous studies of refusals (Besson, Roloff and Paulson, 1998; Saeki and O'Keefe, 1994; Wootton, 1981).

Russell's response, with its spate of forms of fuck, also flouts conventional descriptions of polite behaviour. We suggest that he is drawing on the norms of the team as a community of practice and strengthening his request by drawing on solidarity indicators that they are mates. Certainly Ginette's serene response to the stream of fuck words confirms that they convey no negative affect in this context. But neither does she respond in kind in a way that would confirm Russell's implicit claim on their solidarity.

Example 5 provides further evidence that similar speech acts are typically managed rather differently within the Power Rangers team than they are outside the team. In this instance Ginette is refusing not a fellow team member, but Francie, a status equal from outside the team who works across the factory in a quality assurance role.

\section{Example 5}

Context: Ginette, a Pacific Islander aged 30-34 years, Power Rangers team coordinator, talking to Francie, a Maori aged 35-39.

1. Ginette: [calls]: yo Dirk +

2. Francie: do you have an $\mathrm{NCR}^{7}$ for that (boxes) over there

\footnotetext{
${ }^{7}$ A NCR is a Non Conformance Report, or a sheet filled out when a product is not up to standard.
} 
3. Ginette: yeah I've I'm waiting for a number ++

4. I need to see Vicky about the NCR thing

5. I haven't got a number for it yet

6. Francie: oh how would you get it

7. Ginette: when I get to see Vicky +++

8. Francie: oh how's about you just give it to me now +

9. $\quad$ take a copy of that + so I can compare it

10. and I'll take the number then +++

11. Ginette: (where are they) + do you want it right now

12. Francie: if it's possible [laughs]

13. Ginette: it's just I've left a + I've got um Jennifer's working +

14. going through it as well

15. Francie: oh okay is it possible tomorrow then

16. Ginette: I'll get it to you tomorrow morning yeah

Francie's initial request is direct and clear do you have an NCR for that box over there (line 2). By contrast with the direct way she refused the request of her team mate Russell in Example 4, Ginette's refusal of Francie's request is conventionally polite and extended. She prefaces her refusal with a polite conventional agreement marker yeah and then elaborates in the form of a full explanation I've I'm waiting for a number I need to see Vicky about the NCR thing I haven't got a number for it yet (lines 3-5)

Francie does not simply accept this refusal to comply with her request. She follows up with three further distinct attempts to elicit what she wants oh how would you get it (line 6), and then oh how's about you just give it to me now (lines 8-10) and finally okay is it possible tomorrow then (line 15). The pauses (marked + ) following Francie's requests indicate Ginette's reluctance to respond. Her request for clarification do you want it right now (line 11) buys her time before she provides another explanation (lines 13-14) for why she cannot give Francie the NCR right now. Finally they negotiate a compromise (lines 15-16) and the transaction is satisfactorily brought to completion.

The careful negotiation evident in this exchange indicates that Ginette is being conventionally respectful of Francie's face needs. While pursuing their transactional goals (Francie to see the relevant NCR and Ginette to ensure her team's paper-work is in order before it is checked by Francie) the two women skilfully avoid confrontation and direct disagreement or challenge. The two women have worked together for ten years, and clearly have a friendly relationship, but even so, Francie's status as a non-member of the Power Ranger's team is evident from subtle differences in the way they interact. Ginette is certainly aware of this to some extent, as reflected in her comment that "I generally interact with everyone the same, I don't treat anyone different, although the vocab used may differ." (pers. comm.). In the example above, we in fact see that Ginette uses a range of negative politeness strategies to convey her refusal in an acceptable way-avoidance strategies (lines 3-5, 11, 13-14), pauses (lines 3,7,10), explanations (lines 13-14), and hedges (line 13). In particular, there is no trace of any expletive in this exchange, and certainly the 
expletive fuck is not used to modify Ginette's refusal in this interaction in any way- as Ginette says, she uses 'different vocabulary' depending on whether her interlocutor is a team member or not. She was well aware that the team had a unique style of interaction, one that only core team members could be expected to use and understand: "Our team created a culture that we were all comfortable with. when someone new joined us we obviously took the path of easing them into our culture." (pers. comm.).

\section{Discussion}

\subsection{Negotiating face threatening acts}

Our analysis indicates that the ways in which complaints and refusals are expressed within the Power Rangers team are very different from the ways they are expressed with non-team members, and very different from the ways in which previous research in more middle class contexts suggests. Between team members, both these negatively affective speech acts are typically expressed in very direct, concise and apparently confrontational ways, without elaboration or mitigation, and they are frequently reinforced by the use of expletives. Similar speech acts with people outside of the group tend to be longer, more indirect, and include only mild expletives, if any. Team membership is thus a crucial factor in determining how such speech acts are constructed, negotiated and interpreted. Team members treat each other in ways we might expect family members or intimates to treat each other, using direct and confrontational pragmatic strategies rather than conventionally polite ways of expressing complaints and refusals.

Our research thus demonstrates that in genuine face-to-face spoken interaction (as opposed to elicited discourse completion task data) refusals are typically highly complex speech acts, often involving lengthy negotiations and the use of a number of face saving strategies to accommodate the non-compliant nature of the speech act (c.f. Houck and Gass, 1996: 49).

\subsection{Politeness and the functions of fuck}

As noted above, fuck is widely described and regarded as "a rude and offensive word" and one which even advanced learners of English "should avoid using" (Sinclair, 2001: 635). Yet the data we have gathered on the factory floor attests that, for this team at least, forms of fuck occur frequently in certain contexts and serve a range of functions, including the role of positive politeness strategy. Fuck is regularly associated with expressions of solidarity, including friendly terms of address and speech acts which unambiguously serve the function of solidarity construction; notable here are whinges, which serve to offload negative affect in a safe environment, to release tension, and to maintain rapport between people.

It was also clear, however, that fuck did not occur indiscriminately, even in whinges. Its function as a positive politeness or solidarity marker was confined to members of 
the Power Rangers team within this factory. Among team members it could be used freely, like many other forms of face threatening behaviour. In contrast, in the data we have analysed to date, forms of fuck did not occur outside the team, even between equals, or in a solidarity constructing speech act such as a whinge.

In a further complication of the analysis, forms of fuck also occurred extensively, even in the context of extremely face-threatening acts, between members of the Power Rangers team, but not in interaction with other factory workers. Both direct complaints, as illustrated in example 1, and refusals, as demonstrated in example 4, were typically modified by forms of fuck in the usage of team members.

In such contexts, we suggest that, paradoxically, team members convert the negative affect and strength associated with forms of fuck in standard contexts into a positive attribute in its use in interaction between members of their own community of practice. The inherent strength of the canonical expletive fuck thus contributes to its impact when used between friends and co-workers. It is as if they are saying "I know you so well I can be this rude to you".

Another dimension of the use of fuck in the Power Rangers team is its role in negotiating and expressing different positions in relation to the management structure. The Power Rangers team is nominally a 'self managing' team, with every team member having equal input to decision making and management. Nonetheless, the reality is that some members of the team (e.g., Ginette) have more responsibility and power than others. The use of fuck within the team may at times provide an acceptable way of contesting or mitigating actual or perceived status differences and of defusing any tension associated with this.

Our conclusion, that strong expletives, and especially forms of fuck, are extensively used within the Power Rangers as a positive politeness device, is consistent with the findings of previous studies. For instance, Hay (1994), showed that jocular abuse was used by a small tightly integrated role-playing group to express group membership and solidarity; and Kuiper's (1991) study highlighted the role of sexual humiliation as a group-bonding strategy between players in the locker room after a rugby game. (See also Hughes, 1992; Pilkington, 1998). Our data from the factory floor, a context which has rarely been documented, provides additional support for these findings.

Interestingly, too, given the fact that about a third of the Power Rangers team identify as Samoan, and that Ginette is a Samoan, this interactional style is also consistent with certain styles of Samoan repartee. "Ribbing" one's mates and "having them on" is a common type of interaction in informal contexts; it provides a strong contrast with the very serious and sober nature of Samoan "chiefly" talk in formal contexts (Alfred Hunkin, pers. comm.). A training manager at the factory concurs, suggesting that while joking and direct talk are part of the 'kiwi' communication style as he saw it, the Pacific Island workers in the teams he had worked with over the years seemed particularly adept at light-hearted jocular abuse and playing practical jokes.

Overall, then, for a range of reasons, using expletives in their exchanges with each other clearly contributes to the Power Rangers' sense of solidarity, and thus acts as a positive politeness strategy within this team. Indeed, these usages and their positive 
function within the team's exchanges can be considered an identifying feature of this community of practice.

\section{Conclusion}

Politeness is a complex concept and one which is culturally very slippery, as many recent analyses have demonstrated (e.g. Watts et al., 1992; Fukushima, 2000; LeeWong, 2000; Marquez-Reiter, 2000; Spencer-Oatey, 2000; Eelen, 2001). Acting in ways which are contextually appropriate typically requires extensive understanding of the cultural norms and values of the community of practice involved. Acceptable ways of expressing solidarity and mitigating FTAs cannot be prescribed or predicted, or even understood, without careful ethnographic analysis of the participants' normal everyday patterns of interaction in their usual workplace contexts.

As Lakoff (2001) points out, the detailed analysis of the way language is used in a particular socio-cultural setting provides illuminating insights into the complexity of what is considered "polite" behaviour in different communities of practice. In this paper we have illustrated this point by focusing on one particular socio-pragmatic strategy - the use of forms of the strong expletive fuck by members of a workplace factory team to express positive politeness in redressing the face threat of complaints and refusals on the factory floor.

\section{Transcription conventions}

All names are pseudonyms.

YES Capitals indicate emphatic stress

[laughs] Paralinguistic or descriptive features in square brackets [drawls] :

$+$

Indicates the scope of the paralinguistic feature it accompanies

(3) Pause of 3 seconds

(hello) Transcriber's best guess at an unclear utterance

? $\quad$ Rising or question intonation

solidar- Incomplete or cut-off utterance

\# Signals end of "sentence" where it is ambiguous on paper

...... Section of transcript omitted

\section{References}

Alicke, Mark D., Braun, James C., Glor, Jeffre E., Klotz, M.L., Magee, Jon, Sederholm, Heather, Siegel, Robin, 1992. Complaining behavior in social interaction. Personality and Social Psychology Bulletin 18, 286-295. 
Beebe, Leslie M., Cummings, Martha Clark, 1996. Natural Speech Act Data Versus Written Questionnaire Data: How Data Collection Method Affects Speech Act Performance. In: Sue, Gass, Joy, Neu (Eds.), Speech Acts Across Cultures: Challenges to Communication in a Second Language. Mouton de Gruyter, Berlin/New York.

Bellinger, David, Gleason, Jean Berko, 1982. Sex differences in parental directives to young children. Sex Roles 8, 1123-1139.

Besson, Amber L., Roloff, Michael E., Paulson, Gaylene D., 1998. Preserving face in refusal situations. Communication Research 25, 183-199.

Blum-Kulka, Shoshana, Blondheim, Menahem, Hacohen, Gonen, 2002. Traditions of dispute: from negotiations of talmudic texts to the arena of political discourse in the media. Journal of Pragmatics 34, $1569-1594$.

Blum-Kulka, Shoshana, House, Juliane, Kasper, Gabriele, 1989. Cross-Cultural Pragmatics: Requests and Apologies. Ablex, Norwood, NJ.

Boxer, Diane, 1993. Social distance speech behavior: the case of indirect complaints. Journal of Pragmatics 19, 103-125.

Brown, Penelope, Levinson, Stephen C., 1978. Universals in language usage: politeness phenomena. In: Goody, E.N. (Ed.), Questions and Politeness. Cambridge University Press, Cambridge, pp. 56-310.

Brown, Penelope, Levinson, Stephen C., 1987. Politeness. Some Universals in Language Usage. Cambridge University Press, Cambridge.

Clyne, Michael, 1994. Intercultural Communication at Work. Cultural Values in Discourse. Cambridge University Press, Cambridge.

Coates, Jennifer, 1996. Women Talk. Blackwell, Oxford.

Coates, Jennifer, 2002. Men Talk. Blackwell, Oxford.

Eelen, Gino, 2001. A Critique of Politeness Theories. St Jerome, Manchester.

Ervin-Tripp, Susan M., 1976. Is Sybil there? The structure of some American English directives. Language in Society 5, 25-66.

Frescura, Mariana, 1995. Face orientations in reacting to accusatory complaints: Italians L1, English L1 and Italian as a community language. Pragmatics and Language Learning 6, 79-104.

Fukushima, Saeko, 2000. Requests and Culture: Politeness in English and Japanese. Peter Lang, Bern.

Georgakopoulou, Alexandra, 2001. Arguing about the future: on indirect disagreements in conversations. Journal of Pragmatics 33, 1881-1900.

Ginette (pseudonym), personal communication. Email exchange, April 2003.

Goffman, Erving, 1967. Interaction Ritual. Garden City, New York.

Hanks, Patrick, 1984. Collins English Dictionary. Collins, London.

Hay, Jennifer, 1994. Jocular abuse patterns in mixed-group interactions. Wellington Working Papers in Linguistics 6, 26-55.

Herbert, Robert K., 1989. The ethnography of English compliments and compliment responses: a contrastive sketch. In: Olesky, W. (Ed.), Contrastive Pragmatics. John Benjamins, Amsterdam, pp. 3-35.

Holmes, Janet, 1986. Compliments and compliment responses in New Zealand English. Anthropological Linguistics 28, 485-508.

Holmes, Janet, Nicola, Daly forthcoming. Refusals in the workplace.

Holmes, Janet, Marra, Meredith, 2002. Having a laugh at work: how humour contributes to workplace culture. Journal of Pragmatics 34, 1683-1710.

Holmes, Janet, Stubbe, Maria, 2003a. Power and Politeness in the Workplace: A Sociolinguistic Analysis of Talk at Work. Pearson, Education, Edinburgh.

Holmes, Janet, Stubbe, Maria, 2003b. "Feminine" workplaces: Stereotype and reality. In: Holmes, J., Meyerhoff, M. (Eds.), Handbook of Language and Gender. Blackwell, Malden, Mass, pp. 573-599.

Houck, Noel, Gass, Susan M., 1996. Non-native refusals: a methodological perspective. In: Gass, S.M., Neu, J. (Eds.), Speech Acts Across Cultures. Mouton de Gruyter, New York, pp. 46-63.

Hughes, Susan, 1992. Expletives of lower working-class women. Language in Society 21, 291-303.

Hunkin, Alfred, personal communication. Discussion, November 2002.

Kiesling, Scott, 2001. Now I gotta watch what I say: shifting constructions of gender and dominance in discourse. Journal of Linguistic Anthropology 11, 250-273. 
Kline, Susan L., Floyd, Cathy H., 1990. On the art of saying no: the influence of social cognitive development on messages of refusal. Western Journal of Speech Communication 54, 454 472.

Kuiper, Koenraad, 1991. Sporting formulae in New Zealand English: two models of male solidarity. In: Cheshire, J. (Ed.), English Around the World. Sociolinguistics Perspectives. Cambridge University Press, Cambridge, pp. 200-209.

Lakoff, Robin Tolmach, 2001. Nine ways of looking at apologies: The necessity for interdisciplinary theory and method in discourse analysis. In: Schiffrin, D., Tannen, D., Hamilton, H.E. (Eds.), The Handbook of Discourse Analysis. Blackwell, Oxford, pp. 199-214.

Lee-Wong, Song Mei, 2000. Cross Cultural Communication: Politeness and Face in Chinese Culture. Peter Lang, Frankfurt am Main.

Liao, Chao-chih, Bresnahan, Mary, 1996. A contrastive paradigmatic study on American English and Mandarin refusal strategies. Language Sciences 18, 703-727.

Marquez-Reiter, Rosina, 2000. Linguistic Politeness in Britain and Uruguay. John Benjamins, Amsterdam.

Olshtain Elite, Cohen, Andrew, D., 1983. Apology: a speech act set. In: Wolfson, N., Judd, E. (Eds.), Sociolinguistics and Language Acquisition, Newbury House. Rowley, Mass, pp. 18-35.

Orsman, Bernard, 2001. The Reed Dictionary of New Zealand English, Third Edition. Reed, Auckland.

Owen, Marion, 1983. Apologies and Remedial Interchanges: A Study of Language Use in Social Interaction. Mouton, Walter de Gruyter, Berlin.

Pilkington, Jane, 1998. "Don't try and make out that I'm nice!"' The different strategies women and men use when gossiping. In: Coates, J. (Ed.), Language and Gender: A Reader. Blackwell, Oxford, pp. 254-269.

Saeki, Mimako, O'Keefe, Barbara J., 1994. Refusals and rejections: designing messages to serve multiple goals. Human Communication Research 21, 67-102.

Scott, Suzanne, 2002. Linguistic feature variation within disagreements. Text 22, 301-328.

Sinclair, John, 2001. Collins Cobuild Dictionary for Advanced Learners, Third Edition. Harper Collins, Glasgow.

Spencer-Oatey, Helen (Ed.), 2000. Culturally Speaking: Managing Rapport through Talk Across Cultures. Continuum, London.

Stevens, Paul B., 1993. The pragmatics of "no": some strategies in English and Arabic. Ideal 6, 87-112.

Stubbe, Maria, 2000a. Talk that works: evaluating communication in a factory production team. New Zealand English Journal 14, 55-65.

Stubbe, Maria 2000b. “Just do it ..." Discourse strategies for 'getting the message across' in a factory production team. In: Henderson, J. (Ed.), Proceedings of the 1999 Conference of the Australian Linguistic Society www.arts.uwa.edu.au/LingWWW/als99/proceedings.

Stubbe, Maria, 2001. From office to production line: collecting data for the Wellington Language in the Workplace Project, Language in the Workplace Occasional Papers 2. www.vuw.ac.nz/lals/lwp/ resources/.

Stubbe, Maria, Ingle, Megan, 1999. Collecting natural interaction data in a factory: some methodological challenges. Paper presented at Murdoch Symposium on Talk-in-Interaction, Perth, September 1999. www.vuw.ac.nz/lals/lwp/resources/stubbe_and_ingle_1999.htm.

Thomas, Jenny, 1995. Meaning in Interaction. Longman, London.

Watts, Richard J., Sachiko Ide, Ehlich Konrad, 1992. Politeness in Language: Studies in its History, Theory and Practice Trends in Linguistics. Studies and Monographs 59. Mouton de Gruyter, Berlin.

Wenger, Etienne, 1998. Communities of Practice: Learning, Meaning, and Identity. Cambridge University Press, Cambridge \& New York.

Wootton, Anthony J., 1981. The management of grantings and rejections by parents in request sequences. Semiotica 37, 59-89.

Nicola Daly is a Research Associate at Victoria University of Wellington and a senior tutor in the School of Education at the University of Waikato. Her research interests include gender differences in language use, intonation patterns in New Zealand English and pragmatics in workplace settings. 
Janet Holmes is Professor of Linguistics at Victoria University of Wellington where she teaches courses in sociolinguistics, language and gender and workplace discourse. She is Director of the Wellington Language in the Workplace Project.

Jonathan Newton is a Senior Lecturer and Director of Studies for the DipTESOL Programme at Victoria University of Wellington. He teaches courses in second language acquisition and teaching methodology.

Maria Stubbe is a Research Fellow with the Language in the Workplace Project, in the School of Linguistics and Applied Language Studies at Victoria University of Wellington, and also works as a lecturer and consultant in sociolinguistics and organisational communication. 